\title{
A MODERNIDADE LÍQUIDA NA CIBERPOESIA DE ANTERO DE ALDA*
}

\author{
Débora Silva*
}

RESUMO: Este artigo propõe uma leitura das representações da "modernidade líquida" na obra de Antero de Alda, web-poeta português contemporâneo, que produz e dissemina sua poesia em meio digital. $\mathrm{O}$ autor, recorrendo à convergência de mídias, elabora suas páginas numa composição dinâmica e multidimensional pelo uso de recursos de áudio e vídeo, fotografia, animações, narrativas, poesia cinética e multimídia. A pesquisa desenvolveu-se a partir da análise, interpretação e exercícios de reescrita dos poemas disponíveis no sítio do autor, considerando-se as dimensões referencial e simbólica da linguagem poética e das suas produções hirpermídia. O cerne das análises, nesse enfoque, são as proposições de Zygmunt Bauman sobre as transformações socioculturais do início do século XXI, quando apresenta e discute o conceito de "modernidade líquida", numa contextualização da literatura eletrônica.

PALAVRAS-CHAVE: Cibercultura. Modernidade Líquida. Literatura Eletrônica. Antero de Alda.

Amor líquido. Vida líquida. Vivências liquefeitas... Escorrem pelos dedos... Água e areias do tempo... Leve, leve, muito leve... E solto... Solto como o discurso polifônico que ecoa da modernidade líquida... Este é o cenário que trouxe à luz a poesia de Antero de Alda, web-poeta português que se mostra e deixa falar agora pelo nosso próprio discurso... Também uma leitura, uma releitura... Uma outra fala, uma outra voz e um outro olhar, mais ou menos autêntico, mas igualmente verdadeiro.

Colocar-se ante a poesia de Alda é ter o privilégio de encontrar uma voz e um olhar que mire o tempo presente e visite outros tempos, de maneira crítica e equilibrada, numa perspectiva lúcida e envolvente, sem perder, entretanto, o ethos da liberdade poética. Considerando as condições de produção dos textos

\footnotetext{
* Artigo parcialmente publicado como resultado do Projeto Ensino de Literatura em Hipermédia e Processos Interacionais, fomentado pelo $\mathrm{CNPq} / 2011$, e produzido no âmbito do Projeto "PO.EX'70-80 - Arquivo Digital da Literatura Experimental Portuguesa", financiado pela Fundação para a Ciência e a Tecnologia com fundos do MCTES e do FEDER/UE (Refª: PTDC/CLE-LLI/098270/2008).

"Universidade Estadual de Goiás. Imeio: desants@uol.com.br.
}

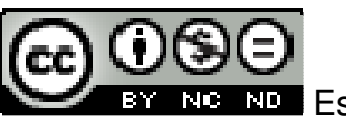

Texto Digital, Florianópolis, v. 8, n. 2, p. 337-360, jul./dez. 2012. ISSNe: 1807-9288 
de Alda, sua empatia com os sofrimentos dos idosos portugueses, das mulheres afegãs do pós-guerra, das crianças do Laos, em toda uma temática de denúncia social e política, não se pode negar que sua obra incita o leitor à crítica de um modelo de pensar imposto e alienante, e busca não mais o retrato, enquanto reflexo da sociedade e do homem, mas a "retratação", no sentido mesmo de "reparação", de construção de um novo modo de ver e questionar o mundo e, a partir disso, promover mudanças.

Efetivamente, na ciberpoesia de Alda, os processos enunciativos que possibilitam ao sujeito lírico se colocar de forma consciente e contestadora em relação ao pensamento institucional, que é a ideologia, partem da ação individual de identificação e resistência até uma ação coletiva de contestar, e não somente assimilar, aquilo que é produto de uma reflexão crítica. É assim que, diante de um realismo maduro, comprometido com os homens de seu tempo, Alda assume uma postura visionária de seu fazer poético, transcendendo os limites da palavra escrita, para registrar, com a força eloquente de suas imagens, o Zeitgeist que demarca a cibercultura.

É em razão dessas forças motrizes que impulsionam a poética do autor que os conceitos de cibecultura, de Lévy (1999); de modernidade líquida, de Bauman (2001); e a noção de hibridismo cultural, de Canclini (2003) parecem estar imbricados nas imagens, sons e signos verbais que emergem no ecrã, quando acessado o sítio de Alda (http://anterodealda.com/). Isso se deve tanto às demandas de suas abordagens temáticas quanto ao formato e ao suporte em que se configuram suas produções.

Deste modo, este artigo se propõe a demonstrar, pela análise da ciberpoesia de Antero de Alda, o quanto se evidencia das representações da modernidade líquida e da cibercultura em sua obra, assim como se configuram os traços dessa cultura híbrida que se forma na contemporaneidade, inerente aos tempos de fronteiras geográficas e temporais superadas pelas tecnologias da comunicação. As análises tiveram como foco os poemas pertencentes às 
séries Retratos e Transfigurações e Scriptpoemas - uma sequência de textos significativa por sua extensão e pluralidade temática e estética na obra do autor.

\section{Cibercultura, hibridismo e modernidade líquida}

Não se pode negar que a sociedade contemporânea tem sido marcada pela instauração de significativos fenômenos sócio-político-econômicos e culturais que configuram uma nova realidade. Como auxílio para compreensão destes fenômenos, recorremos inicialmente às proposições trazidas por Harvey, em $A$ Condição pós-moderna (1996), Bauman, em sua Modernidade líquida (2001) e Canclini, em Globalização imaginada (2003) e Culturas híbridas (2008, [1989]). Para esses autores, a aceleração do tempo e a transgressão dos limites do espaço são características da sociedade contemporânea. O aprofundamento dos processos iniciados no lluminismo e nas revoluções burguesas é algo nítido para esses pensadores, mesmo considerando as discordâncias entre eles. Além desses, Berman (1986) e Hall (2003) trazem grandes contribuições quando se propõem a pensar a modernidade e seus avanços ideológicos, culturais e sociais, em uma visão que, embora conceitualmente diferente, concebe a contemporaneidade como algo fluido, obsessivo e irreversível.

Canclini (2003, p. 29) define o termo "hibridização" como "processos socioculturais nos quais estruturas ou práticas discretas, que existiam de forma separada, se combinam para gerar novas estruturas, objetos e práticas". Filmes, obras literárias, fotografias, esculturas, pinturas e muitas outras formas de produção artística passam a ter componentes em sua concepção que se coadunam com origens que transcendem oriente e ocidente, norte e sul, o que na Internet é potencializado.

Por seu turno, Harvey (1996) dedica-se a reflexões sobre a sociedade do final dos anos de 1980, como também ao que se lhe antecedeu. Ao pensar a obra de arte neste período, o autor se refere à "reprodução eletrônica" e aos "bancos 
de imagens". Naquela década, as discussões sobre o que seria arte, e a questão das reproduções numa política da massa cultural, eram preponderantes. Os sentidos simbólicos de uma cultura massificada em larga escala se tornavam motivo de debates e discussões. As tecnologias da segunda metade do século $X X$ eram percebidas por muitos teóricos e artistas como instrumentos de imposição das elites e também de descaracterização da obra de arte.

Tais percepções são dissonantes às de Lévy e gradativamente incompatíveis com as de Bauman, uma vez que ainda não era possível perceber as novas tecnologias como motivadoras de obras que se modificam constantemente e que, ao invés de massificadas, são crescentemente individualizadas para aqueles que as acessam. Não que a massificação de elementos de culturas dominantes como a americana não tenha ocorrido, mas estão longe de ser o fenômeno totalizante e esmagador, vislumbrado anteriormente.

Um olhar mais atento sobre a sociedade contemporânea e suas produções artísticas suscitam indagações quanto ao que as coletividades humanas estão vivenciando e quais representações produzem de suas realidades. Bauman (2001) oferece a perspectiva da "liquidez", apresentando relações humanas marcadas por características modernas radicalizadas ou aprofundadas, sob as quais as transformações iminentes são uma condição intrínseca do homem.

O advento dessas tecnologias acontece num ambiente social e histórico apontado por Bauman (2001) como "modernidade líquida". As sociedades humanas, segundo o autor, passam por uma radicalização da modernidade no que tange à negação do passado e à reinvenção constante do presente, com o intuito de aperfeiçoar infinitamente o homem e suas criações. Esse ambiente acaba por criar nos indivíduos a sensação de instabilidade e insegurança, diante do imperativo de se reinventar a cada instante. 
Segundo Bauman (2001), as transformações sociais pelas quais passa a sociedade contemporânea em todas as esferas - vida pública, privada, relacionamentos humanos, mundo do trabalho, estado e instituições sociais - é a modernidade líquida, ou seja, é a realidade que muda de forma acelerada, sob a menor pressão, porque não pode manter a mesma forma por muito tempo. Assim ele configura todas as instituições sociais - do estado de bemestar, da família, das relações de trabalho, entre outras. Todas essas instituições perdem espaço, de forma cada vez mais acelerada, para o fenômeno de liquefação, pois a concretude dos sólidos derrete-se, assumindo o estado líquido, ou seja, o impulso de transgredir, de substituir, de acelerar a circulação de mercadorias rentáveis não garante tempo suficiente para que tais instituições se solidifiquem em formas estáveis; perdendo, assim, sua possibilidade de uma maior expectativa de vida e garantindo algumas das características que o estado liquefeito confere às esferas dos relacionamentos humanos: fluidez, maleabilidade, flexibilidade e a capacidade de moldar-se. Esse tempo caracteriza-se pelas transformações sociais precipitadas, dissolvendo e desprendendo os laços afetivos e sociais e assinalando um tempo em que as relações tornam-se efêmeras, numa suposta impressão de liberdade, mas que, por outro lado, evidencia a sensação de desamparo aos indivíduos moderno-líquidos.

Já, para Berman (1986), as experiências da atividade humana que abrangem o tempo, espaço, de si e do outro, as possibilidades, perigos e consequências da vida que são compartilhadas por homens e mulheres em todo o mundo, é o que configura a modernidade. Mais que isso: a reflexão e consciência dessas experiências faz surgir um novo ambiente que, segundo autor, "promete aventura, poder, alegria, crescimento, autotransformação das coisas em redor, mas, ao mesmo tempo, ameaça destruir tudo o que temos, tudo o que sabemos, tudo o que somos" (BERMAN, 1986, p.15). Esse estado de coisas lança as pessoas num turbilhão de desintegração contínua e irrefreável, que liquefaz as fronteiras geográficas, raciais, religiosas e ideológicas. 
Hall assinala que "as sociedades modernas são, portanto, por definição, sociedades de mudança constante rápida e permanente" (HALL, 2003, p.14). Entretanto, a permanência de que fala não se trata de certa rigidez, e sim de uma irreversibilidade dessa mudança em um processo inconcluso e infinito de rupturas e fragmentações no interior do próprio sistema moderno. A sociedade está, assim, constantemente sendo descentrada, atravessada por inúmeras divisões sociais, o que produz uma variedade de diferentes posições sociais e diferentes tipos de sujeito.

Neste sentido, a "liquidez" apresentada por Bauman é uma tentativa, por meio de recursos por vezes metafóricos, de registrar e refletir sobre a inconstância das coisas, dos fatos e dos processos desta sociedade que se lança sobre um novo século, trazendo heranças fortes do projeto anterior de modernidade, pensado desde os primórdios do lluminismo.

Buscando compreender melhor o que Bauman oferece como interpretação da contemporaneidade, é necessário primeiro perceber o que é a modernidade para ele:

Podemos pensar a modernidade como um tempo em que se reflete a ordem - a ordem do mundo, do hábitat humano, do eu humano e da conexão entre os três: um objeto de pensamento, de preocupação, de uma prática ciente de si mesma, cônscia de ser uma prática consciente e preocupada com o vazio que deixaria se parasse ou meramente relaxasse. (BAUMAN, 1999, p. 12)

Desta forma, o homem, a partir do lluminismo, lançou-se ao projeto de ordenar o mundo em que vivia por meio do raciocínio lógico e da ciência. Entretanto, para Bauman (2001), houve um declínio das expectativas iluministas de que é possível um ordenamento da vida e que, assim, estar-se-ia numa trajetória linear e evolutiva para o alcance da perfeição em algum momento futuro. 0 amanhã deixou de ser alvo de esperanças quanto a uma vida e um mundo necessariamente melhores. Os processos de modernização não alcançaram o objetivo de gerar ordem na vida humana, de forma completa e eficiente. 
A sociedade deixou, por isso, de se questionar, não porque não haja questões a serem resolvidas, mas porque não vê solução nas respostas. Pensar sobre si, sobre o mundo, o outro e essas relações, não garantem nenhuma emancipação, liberdade ou consciência crítica da realidade. Por isso, deixa-se de se questionar o social - o que é bem conveniente e vital para a modernidade líquida - e passa-se a se preocupar com o pessoal, o individual. Um fenômeno curioso e paradoxal de individualismo massificante!

Mesmo assim, o dinamismo moderno (fruto de uma velocidade não registrada anteriormente na história) e sua constante tentativa de construção de harmonias sociais persistem e adentram o século XXI, porém de forma mais intensa e aprofundada, gerando a sensação de instabilidade e vulnerabilidade contínuas. Desta forma, destaca Bauman, em suas considerações críticas:

\begin{abstract}
A sociedade que entra no século XXI não é menos "moderna" que a que entrou no século $X X$; o máximo que se pode dizer é que ela é moderna de um modo diferente. $\mathrm{O}$ que a faz tão moderna como era mais ou menos há um século é o que distingue a modernidade de todas as outras formas históricas de convívio humano: a compulsiva e obsessiva, contínua, irrefreável e sempre incompleta modernização; a opressiva e inerradicável, insaciável sede de destruição criativa (ou de criatividade destrutiva, se for o caso: de "limpar o lugar" em nome de um "novo e aperfeiçoado" projeto; de "desmantelar", "cortar", "defasar", "reunir" ou "reduzir", tudo isso em nome da maior capacidade de fazer o mesmo no futuro - em nome da produtividade ou da competitividade). (BAUMAN, 2001, p. 36)
\end{abstract}

O vislumbre de possibilidades de aperfeiçoamento, de redimensionar processos e estruturas, leva a uma "insaciedade" e, consequentemente, ao mover-se em direção a constantes mudanças e transformações, o que acaba por fortalecer a sensação de deslocamento e de não enquadramento. Bauman (2001) afirma que, diferentemente do período anterior, não são mais oferecidos aos indivíduos "lugares" e "reacomodação". Antes mesmo que haja uma acomodação do sujeito em relação ao mundo que o cerca e à realidade que experimenta, é-lhe apresentado o imperativo de que é necessário se modificar, adaptar-se, para que não seja marginalizado ou até mesmo eliminado da sociedade. 
Considerando o contexto da "vida líquida" contemporânea, Bauman (2009, p. 8 , $9 \mathrm{ss)}$ assinala que "livrar-se das coisas tem prioridade sobre adquiri-las". Em decorrência disso, os indivíduos veem-se na tentativa de acelerar sua capacidade de alcançar objetivos e autoidentificações, preparando-se para "largar" suas realizações e referências em direção a uma nova busca em suas vidas. Não há oportunidade para a estabilidade e consideração da concretude das coisas que os cercam, "[...] a ênfase recai em esquecer, apagar, desistir e substituir". Aqui, cabe um friso sobre a última ação apontada: "substituir". Institui-se um ciclo a partir da substituição. Assim, a sobrevivência do sujeito depende do finalizar momentos e sucessos para reiniciar-se com novas conquistas a serem "largadas" e "substituídas".

Nos desdobramentos dessas discussões, Bauman (2009) assinala os mecanismos de como se dá a vida na modernidade líquida, visto que o componente da liquidez das fronteiras territoriais é fundamental no fluxo de destruição de modos de vida elaborados e na formação e novos modos de vida. Isso se realiza em âmbito global, como uma espécie de corrida em que todos se despem a cada momento e vestem-se de maneira renovada para um novo contexto de sobrevivências. A luta individual, sucintamente, é descartar para não ser descartado, concorrendo com todos independentemente de onde se localizem no espaço - continentes e países deixam de ser barreiras para a competição nessa sociedade.

Dentre todas as categorias da modernidade líquida, a individualização e o consumo são as que mais conferem ao sujeito uma liberdade sem precedentes de experimentar, e também a tarefa de enfrentar as consequências dessas escolhas. Todas as variedades que o mercado consumista e o mundo capitalista oferecem alimentam o desejo de multiplicidade individual, do "querer ser quem quiser", querer viver a vida como puder, sem se ater a um estilo único, representar quantos papéis forem necessários em quantos palcos estiverem abertos para apresentações públicas. 
Viver em meio a chances aparentemente infinitas (ou pelo menos em meio ao maior número de chances do que seria razoável experimentar) tem o gosto doce da "liberdade de tornar-se qualquer um". Porém, essa doçura tem um traço amargo porque, enquanto o "tornar-se" sugere que nada está acabado e temos tudo pela frente, a condição de "ser alguém" (que o tornar-se deve assegurar) anuncia o apito final do árbitro, indicando o fim do jogo: "Você não está mais livre quando chega ao final; você não é você, mesmo que tenha se tornado alguém. Estar inacabado, incompleto e subdeterminado é um estado cheio de riscos e ansiedade, mas seu contrário também não traz um prazer pleno, pois fecha antecipadamente o que a liberdade precisa manter aberto." (BAUMAN, 2001, p, 76)

É desse processo vertiginoso e dinâmico de transformações que surgem as inquietações e temores humanos na modernidade líquida. Acompanhar as realidades que se impõem sucessivamente, mas não com linearidade, em ritmo acelerado, não permitindo que haja descompasso entre as habilidades, conhecimentos e identificações que se detêm e o ambiente em que se vive, é um desafio. Desenvolver a capacidade de ser tão líquido quanto o meio que nos envolve, mostra-se, sobretudo, desafiador.

É no cenário traçado por esses autores que se enuncia a produção de Antero Alda. Com efeito, a obra deste ciberpoeta conjuga - na forma, no suporte e no conteúdo - os elementos que compõem a modernidade líquida, como a concebe, com propriedade, Bauman, tendo em vista as reações do homem à instabilidade que the é imposta frente aos desafios da sociedade da informação e do conhecimento.

\section{A poética cine-verbi-voco-visual de Antero de Alda}

A construção imagética da ciberpoesia de Antero de Alda é, sem dúvida, uma das forças motrizes de suas produções. Artista plástico que se dedica à fotografia e à poesia, Alda integrou, na década de 1980, a geração da poesia 
visual portuguesa e, desde 2005, passou a dedicar-se também à poesia eletrônica. Além disso, mantém a atualização de seus blogs, compostos por reflexões e imagens do mundo contemporâneo, mais especificamente 0 europeu.

Alda formou-se em Artes Plásticas pela Faculdade de Belas Artes da Universidade do Porto e se tornou Mestre em Tecnologias Educativas pela Universidade do Minho. Desde o final da década de 1980, destacou-se no cenário artístico europeu por suas produções fotográficas e poéticas, disponibilizadas em sua página na Internet - de natureza essencialmente poética, artística e literária (http://anterodealda.com/) - e em seu blog, de configurações predominantemente ético-políticas, de abertas denúncias sociais e reflexões filosóficas (http://www.anterodealda.com/blog/blog.htm), intitulado "Câmara Antiga". O autor é, assim, um dos agentes da produção artística engajada, que se mostra atento aos movimentos e processos interacionais desencadeados pelas redes de compartilhamento on-line e tudo o que delas decorre.

Relativamente à construção de suas imagens poéticas, o artista mostra-se ousado em seu experimentalismo, ao conjugar linguagem verbal e não-verbal, e empregar, em sua produção poética, variados recursos oferecidos pelas Tecnologias Digitais da Informação e da Comunicação (TDIC), a exemplo de aplicativos como o Flash e o Javascript, a fim de produzir um volume diversificado de poesia cinética e videopoesia, infopoesia interativa e composições intermídia. Sua opção por produzir textos animados, multimídia e interativos não é gratuita, uma vez que isso acarreta uma forte carga de significação, o que é potencializado por uma segunda opção: disponibilizar a produção on-line e não em suportes fechados como CDs e DVDs. Publicar online com recursos multimidiáticos não se trata somente de uma questão técnica, uma vez essa postura acusa uma percepção aberta acerca de aspectos éticos e estéticos implicados no processo de criação e disseminação da obra literária: autoria e direitos autorais, relação autor-leitor, circulação da 
obra, a própria natureza da obra de arte sujeita à sua reprodutibilidade técnica, entre outros. Desta forma, on-line a obra se liquefaz e foge do controle de seu criador, alcançando limites inimagináveis, assim como leituras e interpretações imprevisíveis - situação mais comum na Internet que em suportes estáveis como o livro, que apresenta limitações físicas e econômicas.

Ainda quanto ao suporte e à forma do texto de Alda, é imprescindível referenciar o caráter instantâneo e imediato das obras na tela, assim como a movimentação, a formação e a diluição de textos, imagens e sons. O leitor vivencia uma experiência de contemplação e de imersão simultaneamente, muitas vezes tendo a sensação de texto etéreo, que foge de seu controle e de sua visão (mesmo com a interatividade). A página oficial de Alda na Internet apresenta variadas configurações que se alteram no mesmo fluxo veloz da cibercultura. Observemos o seguinte exemplo:

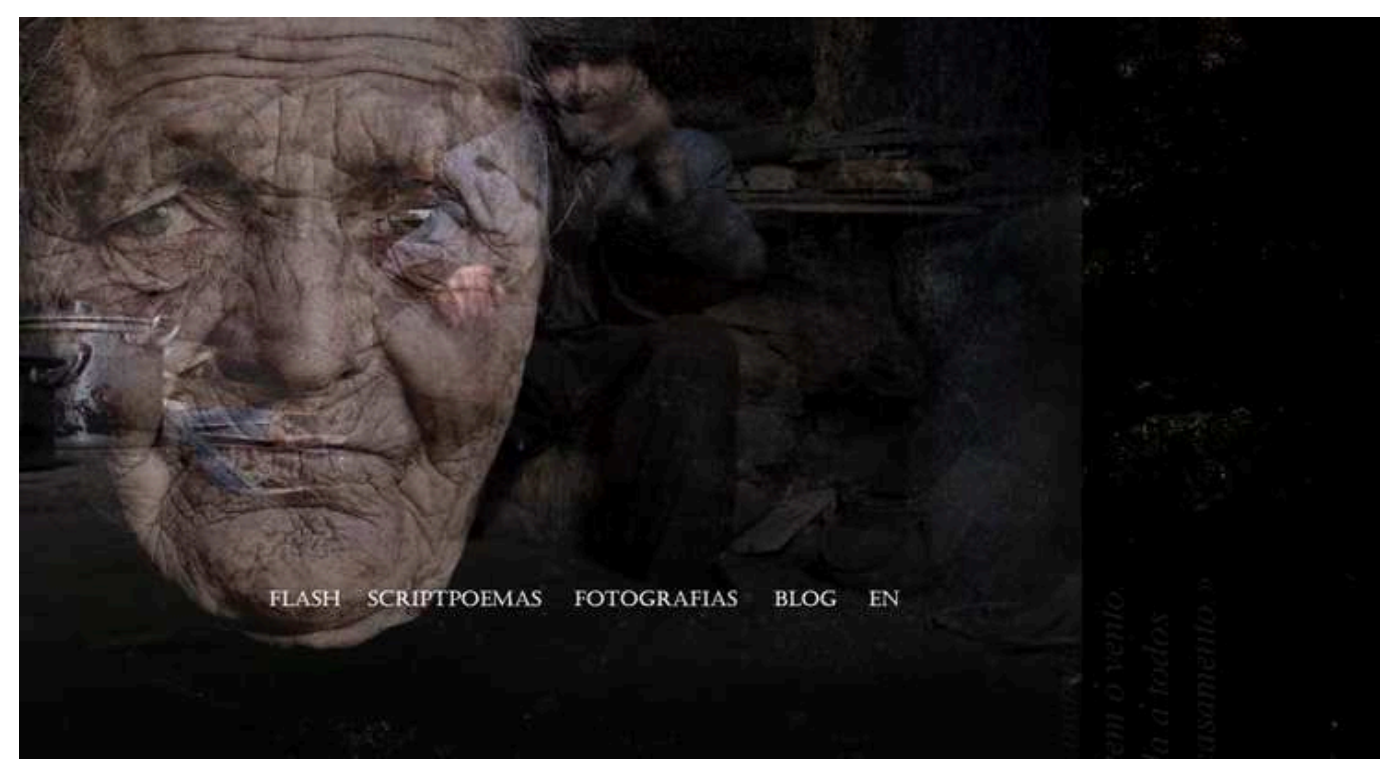

Figura 1 - Página de abertura do sítio de Antero de Alda.

No transcorrer dos anos de 2011/12, o blog teve, em certos períodos, como abertura um de seus trabalhos fotográfico-poéticos intitulado Retrato $e$ Transfigurações. Na ocasião, eram visualizadas, alternadamente na tela, imagens de idosos portugueses, moradores de regiões de cultura tradicional. 
Nessas produções intermídia com fotografia, o autor normalmente apresenta cenários isolados, pelos quais se vislumbram cenas marcantes, como as do sofrimento das crianças no Laos, das mulheres afegãs frente aos horrores do pós-guerra e, ainda, as implicações do capitalismo na vida de pessoas que não podem usufruir desse regime, sofrendo as consequências atuais da cultura do consumo.

Este é o caso dos retratos dos idosos portugueses, condenados a uma condição de vida abandonada e isolada do mundo moderno que, mesmo vivendo em sociedade, são indivíduos que não puderam se reacomodar ou não souberam como fazê-lo e, por isso, foram marginalizados e descartados pela modernidade líquida.

Na sequência de leitura, ao clicar no item "FLASH" na página inicial, abre-se uma nova janela, composta pela imagem de uma senhora portuguesa acompanhada de um poema do autor que reflete sobre o ser mulher no interior de Portugal, com suas cores e dores:

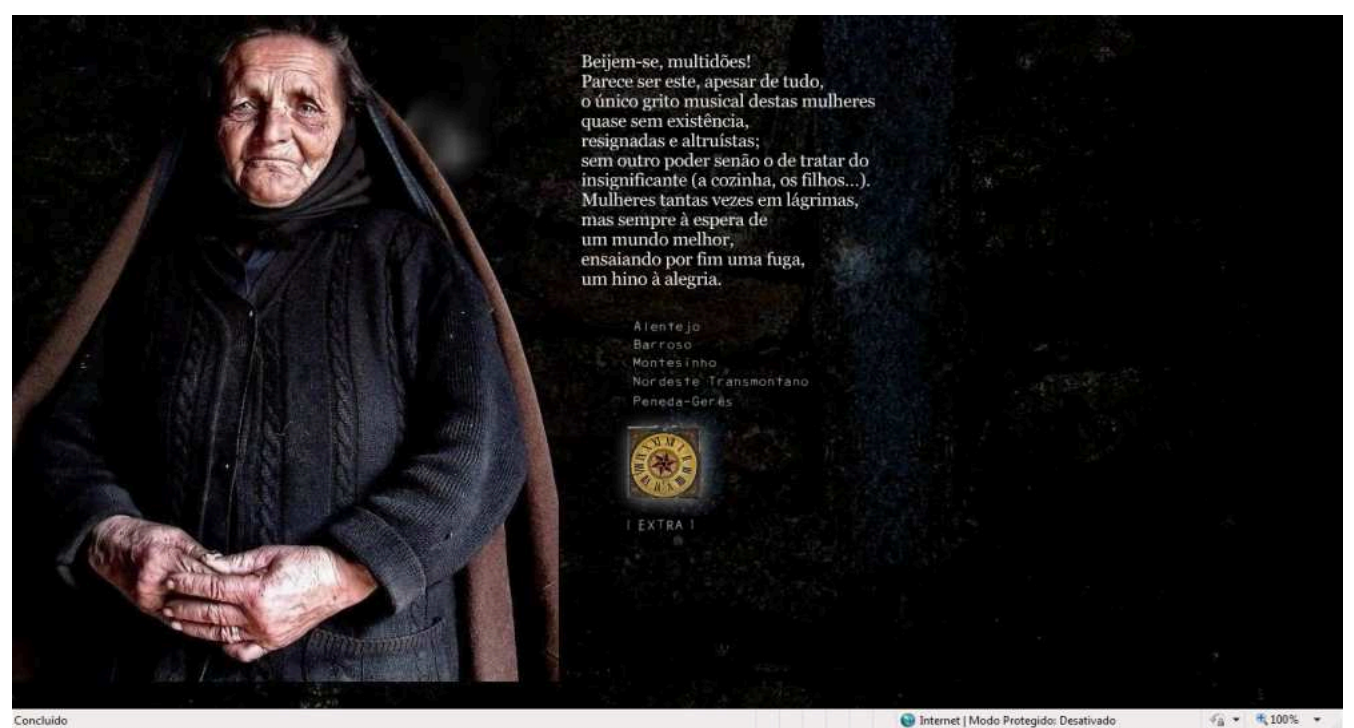

Figura 2 - Página inicial da obra Retrato e Transfigurações.

Depois, surgem as possibilidades de leitura interativa: ao lado da foto e abaixo da última estrofe do poema, estão os nomes das regiões onde as personagens foram fotografadas (Alentejo, Barroso, Montesinho, Nordeste Transmontano, 
Peneda-Gerês) e o leitor pode selecionar a que deseja visualizar primeiro e em sequência. Para cada uma das opções, surgem, na tela, fotografias das mulheres e homens, citações referentes e um pequeno livro de aspecto envelhecido, no qual estão nomes e dados dos indivíduos fotografados. Configura-se uma espécie de "álbum de fotografias" virtual, no qual se veem/ouvem muito além de imagens: as próprias impressões subjetivas e sentimentos desses homens e mulheres comuns, cuja dignidade perdida se resgata pela dimensão da poesia.

Associando-se as imagens de homens e mulheres com cerca de 80 anos, percebe-se que é posta em evidência ao receptor a exclusão da tradição e do passado daqueles que não se renovam e não acompanham as mudanças sociais que ocorrem na modernidade líquida. Os "velhos" são uma representação do que Bauman (2001) indica como inaceitável na realidade de liquidez da sociedade contemporânea. Por isso, são destinados à margem. $O$ abandono e a exclusão são reforçados na obra por uma mosca que pousa sobre a fotografia exposta e caminha sobre o rosto de uma dessas velhinhas, aludindo, metaforicamente, ao processo de reificação do humano e do descarte social das pessoas (a mosca vareja o lixo).

Entretanto, o poeta, ao se apropriar dessas imagens, aliando-as ao seu poema e às citações, redime a dimensão humana desses indivíduos ligados a um modo de vida superado, deslocado dos contextos atuais. Assim também reafirma a quebra de expectativas, ou de compromisso, com a ideia de progresso, permitindo que o passado retorne e se reintegre na obra que compõe esse grande hipertexto, que é a Internet. Esse "retrato" da velhice torna-se ambivalente em Alda, uma vez que, embora esta seja negada pela sociedade contemporânea, é simultaneamente, uma possibilidade de revisitação às tradições e ao passado, permitindo que os indivíduos descartados sobrevivam, em meio à liquidez. 
No sítio do autor, se encontra, ainda, o link SCRIPTPOEMAS, que dá acesso a uma série de textos produzidos em formato intermídia, sendo alguns deles de caráter interativo. Esses Scriptpoemas reúnem uma coletânea extensa de poemas criados em Javascript e em Flash, construídos todos com a recorrência metafórica da palavra POEMA. Nestes encontramos as produções intermídia "Poema objecto" e "Poema negro", em que a palavra "poema" se altera, sendo composta e decomposta ante os olhos do utente-leitor. Retornando-se, então, à página inicial e clicando-se em Scriptpoemas, é aberta a navegação, sob uma apresentação de Rui Torres, a um painel com uma serie de 82 poemas:

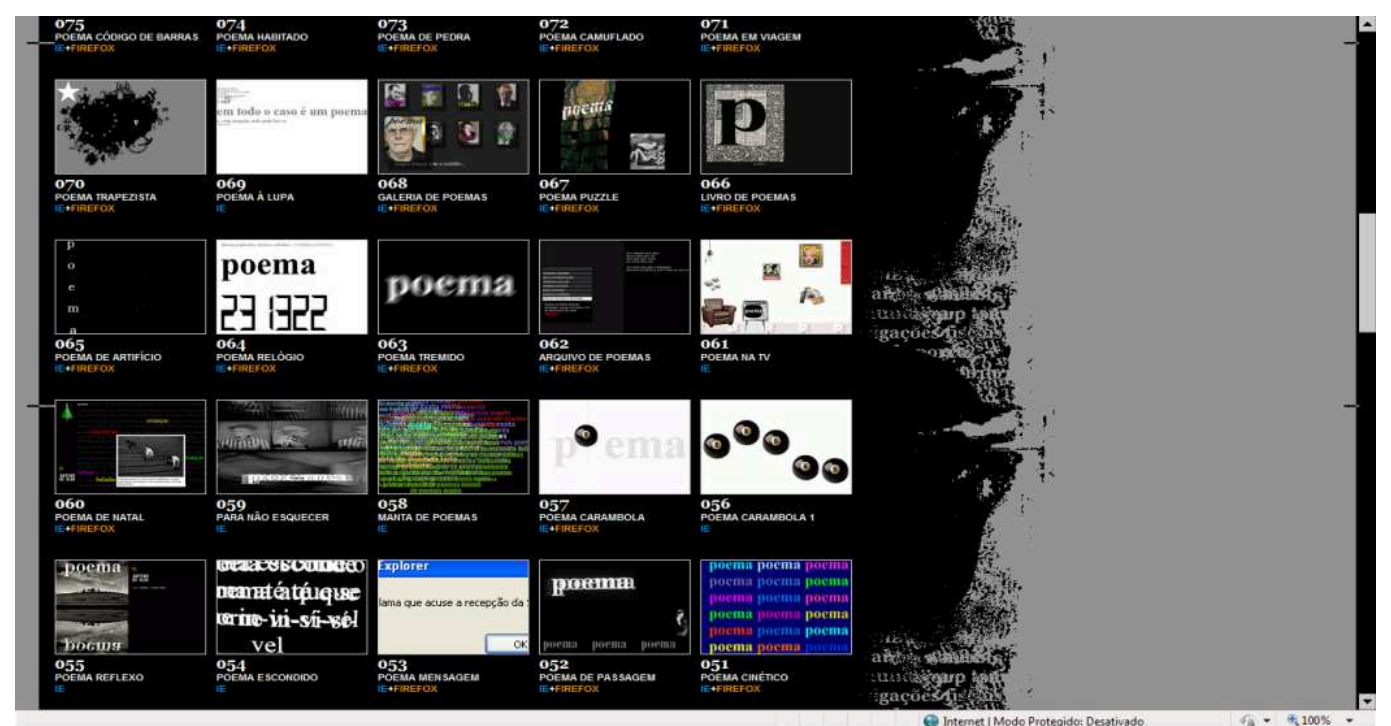

Figura 3 - Painel com Scriptpoemas para escolha do leitor.

Basta abrir a página de Alda para perceber que o caráter multimídia dessas produções é marcadamente integrado aos elementos verbais, descortinando variadas possibilidades de leituras e interpretações estéticas, como bem assinala o crítico e web-poeta Rui Torres em sua apresentação:

A sua série de Scriptpoemas representa, e apresenta, de um modo caligramático, a relação entre significado e significante no signo digital. Através da repetição da palavra "Poema", apresentam-se variações ao nível da expressão que conferem à relação sígnica uma motivação pouco usual. Assim, o "poema-flutuante" flutua, o "poemaelástico" estica, o "poema ao vento" voa, o "poema-reflexo" reflecte, o "poema de passagem" passa... A programação do poema e do objecto pelo conteúdo da sua expressão pode estar enraizada na ideia de que há uma coincidência das palavras com as coisas que a poesia pode revelar. Fenomenologia do digital, aqui, descritivo e criativo se ligam, no sentido de desautomatizar a percepção 
banalizada que temos do novo paradigma digital que se vai impondo. (TORRES, 2008, on-line)

Esse processo de construção intersemiótica intensifica, no nível de sinestesias puras, a recepção do poema, que é fruído com toda a potencialidade do signo cine-verbi-voco-visual da ciberliteratura. É ele quem enriquece, por exemplo, o "Poema Negro", ao provocar o leitor a imergir no discurso de Martin Luther King e na música Agnus Dei, de Samuel Berber e All Angels. A melodia ambienta a leitura das imagens e palavras, da alternância de cores e formas. Fato que se dá em curto espaço de tempo e parece pensado exatamente para esse leitor imersivo, nativo em meios digitais. Captar o texto verbal simultaneamente aos demais elementos apresentados exige muita atenção durante a leitura. Mais que isso, permite perceber a obra como uma expressão duma cultura em que a velocidade com que imagens se fazem e se desfazem diante do leitor é intensa e crescente.

$\mathrm{Na}$ mesma linha do questionamento da ideologia, apresenta-se o "Poema Objecto". Na página inicial, sob a ação do leitor ao acessar o texto, imagens de objetos e faces humanas alternam-se velozmente quando, ao lado, surge, por instantes, o verso: "Por favor, faça de mim um poema!". O cursor, quando deslocado pelo leitor, emite dezenas de repetições do vocábulo "objecto", que constrói a palavra "poema". Nesse poema, o processo de auto-referenciação, transitando entre conotação e denotação, possibilita interpretações diversas. Os elementos típicos do cotidiano que aparecem na tela seriam material digno de um poema? Estes, além de suscitarem reflexões sobre objetos de desejo e consumo (cigarro, gravata, sapato, relógio, telefone etc.), incitam o leitor a questionar sobre o que seria "digno" de tornar-se Poesia. Qual o material literário do poema? A vida, que passa em ritmo alucinante diante das janelas (windows) da web ainda pode transformar-se em Poesia? 


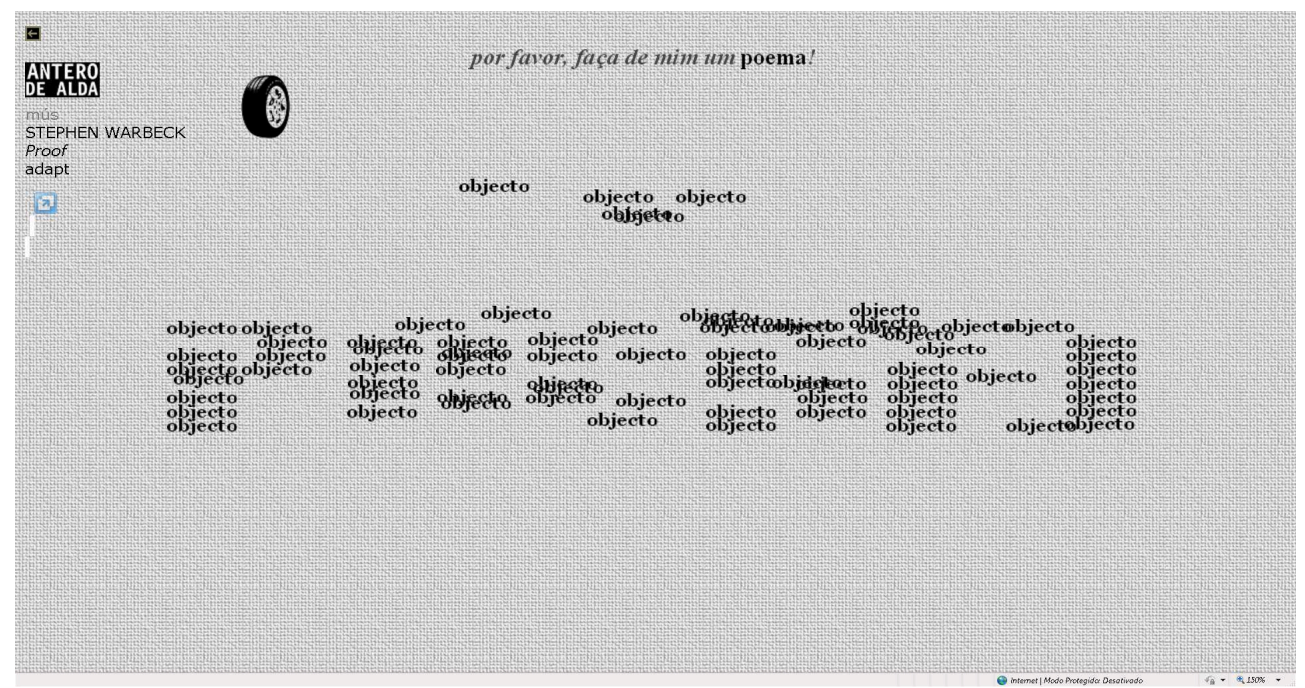

Figura 4 - Poema Objecto com intervenção do leitor

Aqui ressurge a temática relacionada ao padrão de vida contemporâneo, focado no consumismo, como também no posterior descarte dos objetos consumidos, incluindo os seres humanos (já que rostos humanos se alternam aos objetos assinalados na tela). Processos como esses são apontados por Bauman (2001) como "radicalizados" na modernidade líquida, uma vez que poder consumir e posteriormente produzir lixo significa, ironicamente, alcançar sucesso material na sociedade do século XXI. As possibilidades de interação do leitor com o poema se evidenciam pelo manuseio do cursor, que distribui pela tela do computador o vocábulo "objecto" em profusão. Este vocábulo "multiplicado" compõe a palavra POEMA. Ao mesmo tempo, a palavra "objecto" transita continuamente dos objetos figurados na tela ao vocábulo "poema", numa simulação do próprio fazer poético, do processo de criação digital, que é livre e condicionado, ao mesmo tempo, pelo programa oferecido ao leitorcriador.

Outra obra que compõe a série dos Scriptpoemas é o "Poema Puzzle". O poema consiste na presença, num fundo escuro, da tela "O grito", de Edward Munch, sobre a qual se encontra grafada a palavra POEMA. Mais à direita, no canto inferior do ecrã, mostra-se uma "janela" em que desfilam imagens que fazem referência a fatos marcantes do século XX, como a guerra do Vietnã, as chacinas e holocaustos provocados pelas duas Grandes Guerras e outros 
conflitos. Como trilha sonora, a música de abertura da ópera Carmina Burana, de Carl Off, se anuncia, de modo impactante.

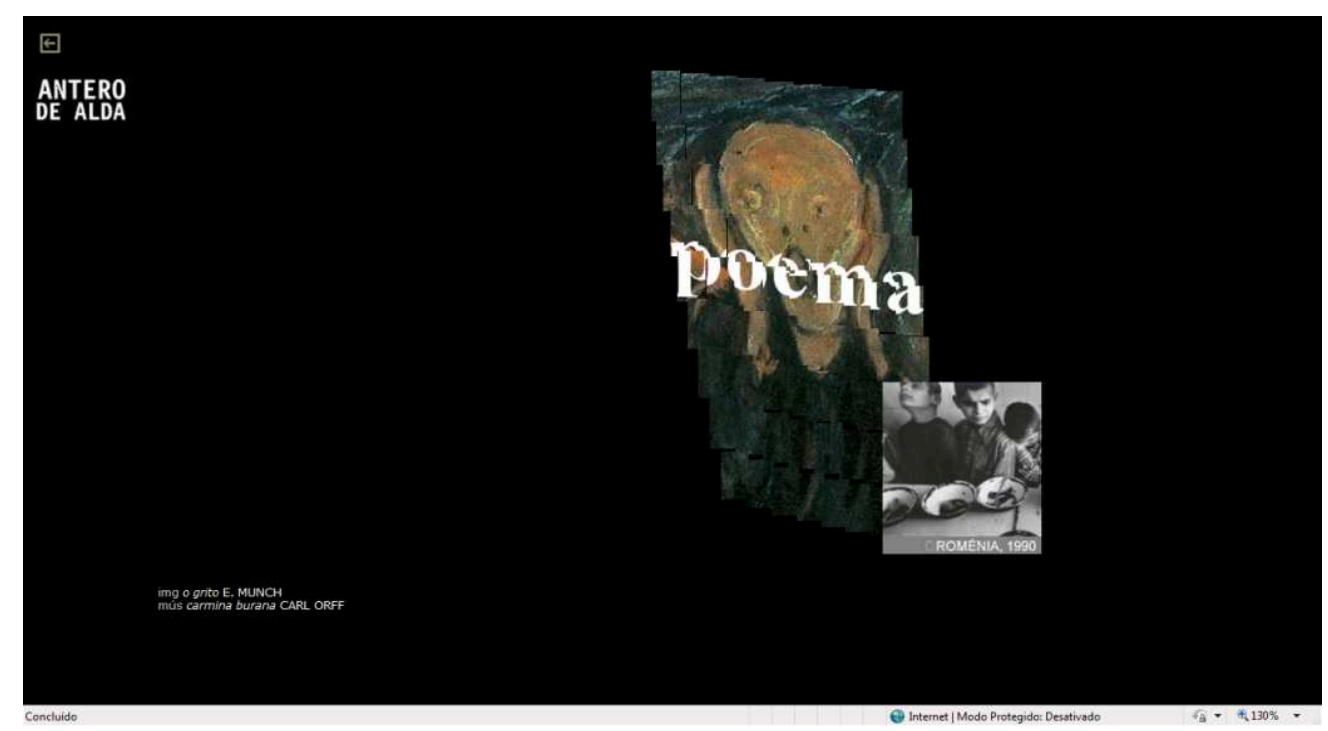

Figura 5 - Apresentação inicial do Poema Puzzle.

Conforme o leitor desliza o cursor sobre a reprodução de "O Grito", a tela se fragmenta em vários pedaços, como um espelho partido, e lentamente volta à sua formação original. Ao passar o cursor no centro da tela, onde se inscreve a palavra POEMA, grafada em branco, o leitor desencadeia um processo que materializa o grito angustiado de Munch, que ecoa dilacerado da enorme boca que se abre no centro do ecrã:

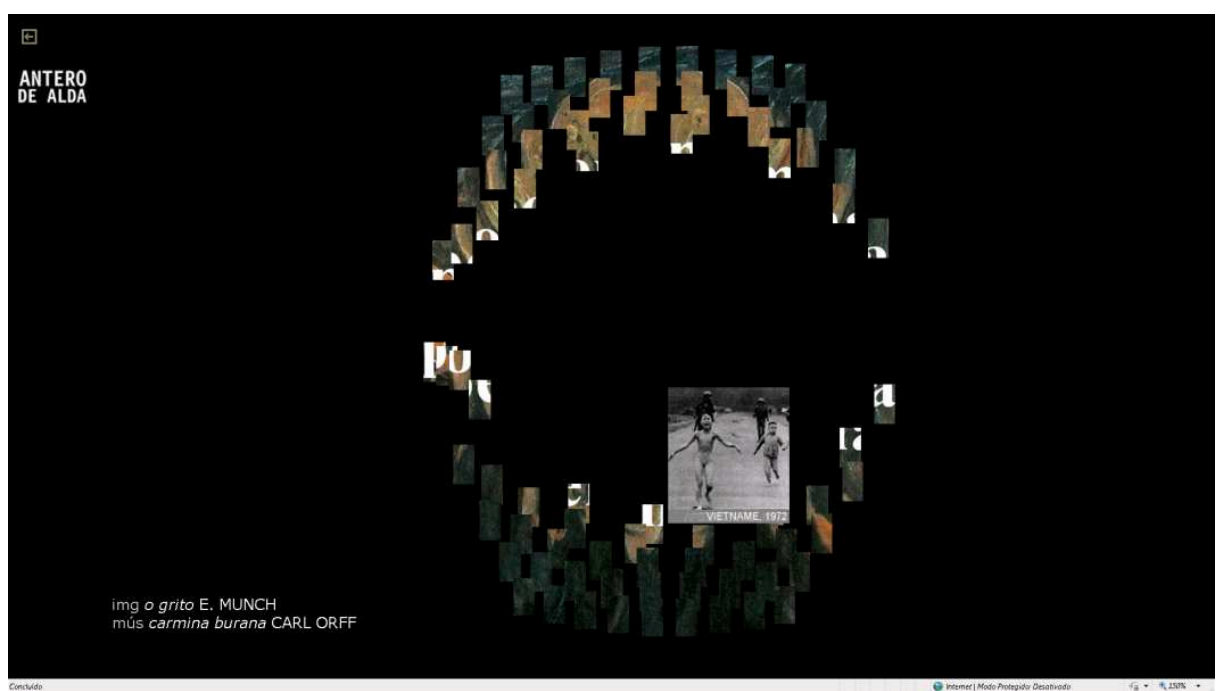

Figura 6 - Poema após interatividade do leitor.

Neste poema, a tela de Munch ganha nova conotação. A música forte e grave, acompanhada pelo dispersar da pintura em pedaços, reafirma o grito violento e 
dilacerado de toda a Humanidade. As imagens abaixo - Camboja, Vietnã, Romênia, Afeganistão - rememoram a violência e a miséria que se espalharam pelo mundo durante o século passado, uma vez que as fotografias estão sempre se alternando, multiplicando e renovando sempre as cenas de horror.

O grito expresso é global. Nele, o autor retoma a voz dos excluídos e marginalizados, aos quais não foram oferecidas oportunidades de integração à renovação - nem mesmo de participação - numa sociedade que se "reinventa" constantemente. São integrantes de culturas tradicionais, que vivem em regiões desvalorizadas, nos processos políticos e econômicos, em escala mundial. O apagamento de uma imagem para o surgimento de outra, como na diluição da pintura de Munch, leva o fruidor do poema ao questionamento sobre instabilidade e a falta de força unívoca, de união entre as personagens da tragédia humana, que se propaga em proporções globais.

Nas obras aqui citadas, como em outros poemas disponíveis na página, surgem imagens de minorias (mulheres, negros, crianças, árabes, africanos, velhos) que disputam espaço na sociedade e que lutam por reconhecimento de suas demandas e identidades. São aqueles que se encontram deslocados na modernidade líquida e que não acompanham as transformações constantes. $O$ autor demonstra, mesmo que indiretamente, o fim dos vínculos dos indivíduos com as lutas de classe, marcante nas perspectivas marxistas de análise, e o surgimento de disputas difusas entre grupos pequenos e discriminados socialmente.

"Poema em Viagem" foi escolhido para objeto desta análise, por ser um poema interativo que apresenta retratos de sociedades e culturas híbridas, apresentando a mesma problemática de abandono e alienação dos sujeitos. Nesse poema, é possível perceber algumas características bem peculiares da ideologia que se imprime à modernidade liquefeita. O poema expõe fotografias de oito localidades, sendo elas: Brasil, Letônia, Cabo Verde, Estados Unidos da América, Índia, Bulgária, África do Sul e a Paris da década de 1950. 
Cada um desses locais, ordenados horizontalmente, tem um link, e são todos delimitados por dois pequenos marcadores textuais nas extremidades. Passando-se o cursor nesses marcadores, abre-se então uma estrutura de versos e, para cada um dos locais indicados, abre-se uma fotografia. Em todas as exibições, as letras da palavra "poema" vão subindo na tela e podem ser deslocadas aleatoriamente com o movimento do cursor. No primeiro marcador aparecem os versos:

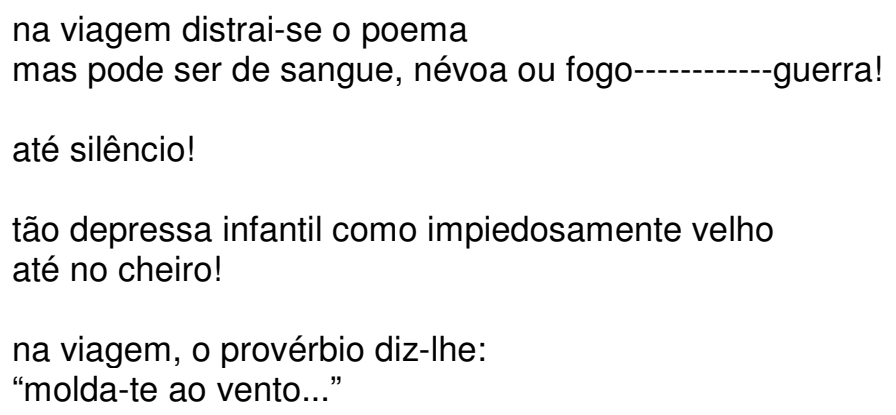

Os versos fazem alusão ao que pode ser encontrado em viagens, desde que se passe a observar para além dos condicionamentos provocados por apelos publicitários: névoa, fogo, guerra, sofrimento e pobreza - elementos que a ideologia de mercado capitalista tende a negar que existam (a fim de vender imagens turísticas de países irreais) e que sinalizam as mortes encobertas, anônimas, escondidas.

Todo o poema se desenvolve com uma música grave de fundo, que intensifica a força das imagens. As imagens surgem em referência a cada um dos locais que compõem a obra, trazendo nova significação aos versos iniciais do poema: crianças pequenas atrás de grades, num parapeito velho e desgastado, com brinquedos quebrados, representam o Brasil; uma mãe obesa nua segurando um bebê no colo representa a América do Norte; um corpo de um jovem branco na mesa de um necrotério aparentemente clandestino é a imagem da África. Ao fim desta série de fotografias, no mínimo, insólitas, a imagem de um beijo de amor na Paris do pós-guerra, mimetiza, em preto e branco, a cena final de um romance cinematográfico! 
Com efeito, os estereótipos dessas nacionalidades são explorados ao máximo diante do leitor. As imagens mostram uma cultura de descarte, de desvalorização do humano, ante um mundo que tem pressa e que impulsiona os que correm nesse fluxo e que atropela os que, por vários motivos, não podem correr. Nesse sentido, Alda busca tornar visível uma realidade que tem sido negada e até mesmo neutralizada, dando voz ao sofrimento de pessoas que foram silenciadas, ou ignoradas, e condenadas a permanecer em um estado insatisfatório para elas, mas que reafirma a ideologia consumista e capitalista, levando-as a querer mudar, sem, no entanto, oferecer possibilidades para isso. Tal situação impulsiona as demais pessoas para a certeza de que não querem pertencer a uma classe descartada. Para o autor, mais importantes que os países, seus sistemas econômicos, políticos, valores sociais e religiosos, são as pessoas que constroem essas realidades, que a sustentam e que são vítimas da própria condição que as envolve e da herança dos que vieram antes delas, mas que acabaram por determinar essas condições de vida.

Mais uma vez a produção de Alda transcende tempo e espaço, pensa 0 mundo, partindo, entretanto, de fenômenos locais, a fim de definir identidades e questionar as interterritorialidades alienantes. Imagens, textos e letras em movimento reforçam a ideia de falta de controle sobre os fatos, retomando a metáfora do vento. A vida líquida de Bauman (2009) estaria aqui representada e pensada, assim como a hibridização indicada por Canclini (2003). Ao se passar o cursor no último marcador, aparecem os três versos seguintes:

vento!

não sejas cruel

se me rasgas o caminho no rosto.

O silêncio (inter)dito na metáfora do vento aparece em posição de destaque no poema como fator tão violento como os demais, uma vez que a atitude de silenciar as mazelas da sociedade é o que impulsiona o consumo e a indiferença. Efetivamente, Berman considera que, nesse modelo de 
organização social e ideológica, "tudo é absurdo, mas nada é chocante, porque todos se acostumam a tudo. Este é um mundo em que o bom, o mau, o belo, o feio, a verdade, a virtude, têm uma existência apenas local e limitada" (BERMAN, 1986, p.17).

Negar o sofrimento das pessoas é justamente o que as faz sofrer com mais intensidade. É a guerra que se tem de combater; é o fogo que devora depressa e impiedosamente as comunidades marginalizadas, descartadas, velhas "até no cheiro". O que resta, então, é moldar-se, acompanhar o fluxo moderno líquido obsessivo e irrefreável, ainda que, para uma grande maioria, cruel. $\mathrm{O}$ que resta é a postura alienante de alimentar o sonho cor de rosa de um "beijo de amor em Paris"?! (La vie en rose).

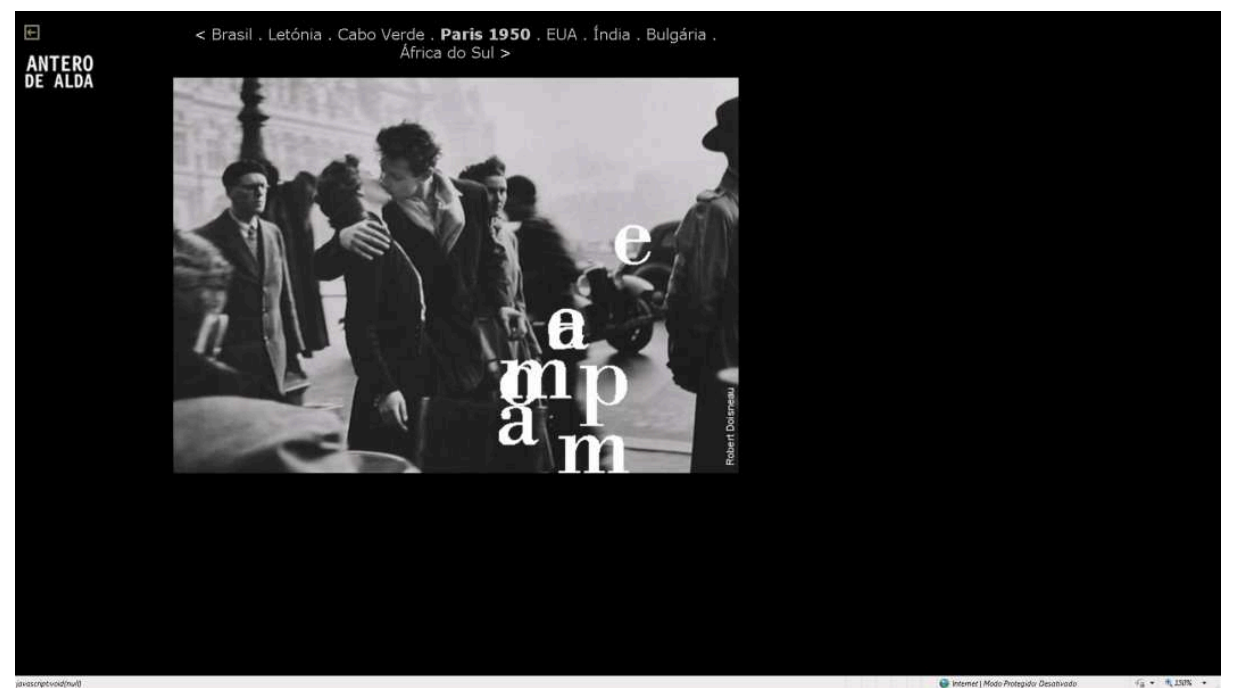

Figura 7 - Poema em Viagem (Paris, 1950)

O modo de execução do poema na tela é completamente interativo. Assim, a ordem e o número de vezes que se reproduz uma imagem fica a escolha do leitor, que pode ver ou não todas as imagens, ler ou não todos os versos ou fechar o poema, como também pode lê-lo várias vezes, rever muitas vezes uma mesma imagem e ainda interagir com as letras da palavra POEMA, que sobem levemente a página, à semelhança de bolhas de sabão sopradas ao vento... A gratuidade da vida que passa no ritmo constante das mudanças se materializa no poema pela instabilidade efêmera dessa imagem. Cada reprodução do poema não será a mesma, sendo infinitas as possibilidades de 
releitura, atendendo-se ao desejo individual de "consumo" do próprio poema, vítima ele mesmo de sua própria denúncia!

\section{Considerações finais}

Como pudemos demonstrar nessas reflexões, a obra de Antero de Alda emprega recursos típicos da ciberliteratura, como a convergência de mídias, a fragmentação do texto, os efeitos cine-verbi-voco-visuais da linguagem e a interatividade, para elaborar textos de caráter literário e natureza poética. Nitidamente, tanto na forma quanto no conteúdo, a modernidade líquida é abordada e representada em sua poesia ao serem retomados conflitos referentes à exclusão social e marginalização de minorias, como também a interferência da política e da economia globais sobre os indivíduos, intensificando o descarte de modos de vida tradicionais, inclusive por meio de guerras e de ações deliberadas de extermínio. Desta forma, Alda produz uma literatura envolvida com as questões de seu tempo, para não eximir-se do papel fundamental do escritor: o de comprometer-se com tudo aquilo que diz respeito ao humano, demasiado humano.

Assim, pudemos constatar, nesse estudo, que o que Bauman (2001) nos apresenta como sendo a característica central das sociedades humanas contemporâneas, qual seja, a liquidez dos conteúdos existenciais e a mudança ininterrupta, é o elemento que integra os textos de Alda aqui analisados e interpretados. De fato, ao usufruir a poesia eletrônica de Alda, não se pode negar o impacto dessas produções no jovem leitor (como se pôde constatar nas oficinas de leitura de poesia e escrita criativa, realizadas ao longo da pesquisa, conforme consta em: http://pensandociberliteratura.blogspot.com).

É assim que se nos impõe um maior tempo de análise, de reflexão sobre as contribuições do ensino de literatura e da prática da leitura e da escrita na formação das novas gerações, a fim de garantir a elas o direito à educação estética, à conscientização de sua autonomia enquanto sujeitos, numa nova 
perspectiva de individualidade, de conquista da liberdade no ambiente de consumo e da tentativa de retorno ao sentimento de pertencimento à Humanidade, que é o que nos identifica e diferencia.

\section{THE “LIQUID MODERNITY” IN ANTERO DE ALDAS'S CYBERPOETRY}

ABSTRACT: This article proposes a reading of the representations of "liquid modernity" in Antero de Alda's work. He is a contemporary Portuguese web poet who produces and disseminates his poetry in digital resource. The author, be taking the convergence of Medias, elaborates his pages in a dynamic and multidimensional composition by the use of resources of audio and video, photographs, animations, narratives, kinetics poetry and multimedia. The research was developed from the analysis, interpretation and rewriting exercises of the author's poems (available on Alda's site), considering the referential and symbolical dimensions of poetry language and his productions on hypermedia. The center of the analysis, on this focus, are the propositions of Zygmunt Bauman about the socialcultural transformations from the beginning of the XXI century, when he presents and discusses the concept of "liquid modernity", in a contextualization of the electronic literature.

KEYWORDS: Cyberliterature. Liquid Modernity. Electronic Literature. Antero de Alda.

\section{Referências}

BARBOSA, João Alexandre. As ilusões da modernidade. São Paulo: Perspectiva, 1986.

BERMAN, Marshall, Tudo que é sólido desmancha no ar. A Aventura da modernidade. São Paulo, Companhia das Letras, 1986.

1999.

Modernidade e ambivalência. Rio de Janeiro: Jorge Zahar Ed.,

Modernidade líquida. Rio de Janeiro: Zahar, 2001.

Vida líquida. Rio de Janeiro: Jorge Zahar Ed., 2009.

CANCLINI, Néstor García. A globalização imaginada. São Paulo: lluminuras, 2003.

Culturas híbridas: Estratégias para entrar e sair da modernidade. São Paulo: EDUSP, 2008[1989].

HALL, Stuart. A identidade cultural na pós-modernidade. Rio de Janeiro: DP\&A, 2003. 
HARVEY, David. A condição pós-moderna. São Paulo: Edições Loyola, 1996. HOBSBAWM, Erick. Era dos extremos: o breve século XX 1914-1991. São Paulo: Companhia das Letras, 2011.

LEVY, Pierre. Cibercultura. São Paulo: Ed. 34,1999.

REIS, Pedro. Média digitais: novos terrenos para a expansão da textualidade. In: Cibertextualidades n. 1. Porto: jan/dez. 2006. p. 43-52. ISSN: 1646-4435

TORRES, R. Transformação, transposição e variação na ciberliteratura de língua portuguesa, 2008. Disponível em: http://telepoesis.net/papers. Acesso em: 26 de jul. 2012.

Texto recebido em 31/10/2012. 